\title{
Efeito de Fontes de Silício na Incidência e na Severidade da Antracnose do Feijoeiro*
}

\author{
Sylvia R. G. Moraes ${ }^{1 * *}$, Edson A. Pozza ${ }^{1 * * *}$, Eduardo Alves ${ }^{1}$, Adélia A. A. Pozza ${ }^{2}$, Janice G. Carvalho ${ }^{2 * * *}$, \\ Paulo H. Lima ${ }^{1}$ \& Alex O. Botelho ${ }^{1}$
}

${ }^{1}$ Departamento de Fitopatologia; e-mail: sylmoraes@yahoo.com.br; ²Departamento de Ciência do Solo; e-mail: alana@ufla.br; janicegc@ufla.br; Universidade Federal de Lavras, Cx. Postal 3037, CEP 37200-000, Lavras, MG, Fax. (035) 3829-1283, e-mail: eapozza@ufla.br

(Aceito para publicação em 27/10/2005)

Autor para correspondência: Edson Ampélio Pozza

MORAES, S.R.G., POZZA, E.A., ALVES, E., POZZA, A.A.A., CARVALHO, J.G., LIMA, P.H. \& BOTELHO, A.O. Efeito de fontes de silício na incidência e na severidade da antracnose do feijoeiro. Fitopatologia Brasileira 31:069-075. 2006.

\section{RESUMO}

Foram realizados três experimentos para estudar a influência do silício na redução da antracnose, causada por Colletotrichum lindemuthianum, em feijoeiro (Phaseolum vulgaris). No primeiro experimento plantas tratadas com silicato de cálcio foram inoculadas com $0,10^{3}, 10^{4}, 5 \times 10^{4}, 10^{5}, 5 \times 10^{5}$ e $10^{6}$ conídios/ml de $C$. lindemuthianum. Na concentração de $10^{6}$ conídios/ml avaliou-se a diferença entre o silicato de cálcio e uma fonte de cálcio (óxido de cálcio). No segundo experimento foi avaliado o silicato de cálcio e de sódio na redução da antracnose. No terceiro experimento, por meio da microscopia eletrônica de varredura (MEV) e da microanálise de raios-X (MAX), estudou-se o efeito do silício nos mecanismos de resistência. Foram realizadas cinco avaliações da doença, utilizadas para calcular a área abaixo da curva de progresso da incidência (AACPI), da severidade (AACPS) e a duração da área foliar sadia (HAD), nos dois primeiros experimentos. Com o aumento da concentração do inóculo houve aumento na AACPI e AACPS e redução na HAD, porém a testemunha inoculada com a maior concentração de inóculo, e tratada apenas com cálcio (CaO), sem silicato, teve maiores AACPI e AACPS do que as plantas tratadas com silicato de cálcio. No segundo experimento, a menor AACPS e maior HAD foram obtidas no tratamento com silicato de sódio via foliar, que proporcionou redução de 62,4\% na AACPS. Na MEV e na microanálise de raios X não se observaram a formação de barreira física e o acúmulo de silício externamente com a aplicação de silicato de cálcio, embora o elemento tenha contribuído para reduzir a antracnose.

Palavras-chave adicionais: Colletotrichum lindemuthianum, nutrição mineral, concentração de inóculo, Phaseolus vulgaris.

\begin{abstract}
Effects of silicon sources on the incidence and severity of the common beans anthracnose

Three experiments were performed to study the influence of the silicon on the reduction of the common bean (Phaseolum vulgaris) anthracnose. The first experiment involved a plant fertilized with calcium silicate and different inoculum concentrations of the Colletotrichum lindemuthianum $\left(0,10^{3}, 10^{4}, 5 \times 10^{4}, 10^{5}, 5 \times 10^{5}\right.$ and $10^{6}$ conidia/ml). In the concentration $10^{6}$ conidia/ml the difference between calcium silicate and calcium oxide was evaluated for effects on the disease. The second experiment evaluated the influence of sodium and calcium silicate on the reduction of the anthracnose. In the third experiment, the scanning electron microscopy (SEM) and X-ray micro-analysis (EDAX) were used to study the effect of the silicon on the plant resistance mechanism. Five evaluations of the incidence, severity and leaf area were done, in the first and second experiment. Disease evaluation was made using area under disease progress curve for incidence (AUDPCI) and severity (AUDPCS) and healthy leaf area duration (HAD). Inoculum concentration was found to increase the AUDPCI and AUDPCS. In contrast, the HAD had decreased. Fertilization of plants with calcium silicate significantly reduced the AUDPCI and AUDPCS, when compared to inoculated control and fertilized plants by calcium oxide (CaO) with higher inoculum concentration. On the second trial, the application of sodium silicate on the leaves of the bean plant reduced AUDPCS by $62,4 \%$ when compared to control. When the treated leaves were scanned with SEM and EDAX was performed, although the silicon had reduced the disease, no accumulation of an external silicon barrier was observed with application of the element.
\end{abstract}

Additional keywords: Colletotrichum lindemuthianum, mineral nutrition, inoculum concentration, Phaseolus vulgaris.

\section{INTRODUÇÃO}

As doenças do feijoeiro (Phaseolus vulgaris L.) constituem umas das principais causas da baixa produti-

\footnotetext{
*Parte da dissertação de Mestrado da primeira autora. Universidade Federal de Lavras (2004)

***Bolsista da CAPES

***Bolsistas do CNPq
}

vidade dessa leguminosa no país. Dentre estas, destaca-se a antracnose, causada por Colletotrichum lindemuthianum (Sacc. et Magn.) Scrib. Essa doença ocorre principalmente em condições de alta umidade e temperaturas moderadas, podendo provocar perdas na produção de até 100\% (Chaves, 1980).

Essas perdas podem ser minimizadas com a utilização de estratégias de manejo, como a nutrição mineral. A correta 
utilização de certos nutrientes pode contribuir para reduzir a intensidade da doença durante o ciclo da cultura. No entanto, outros fatores, como a quantidade e a eficiência do inóculo inicial $\left(\mathrm{y}_{0}\right)$, podem influenciar a taxa de progresso das epidemias (Campbell \& Madden, 1990). Dependendo da quantidade de inóculo, as barreiras física e química associadas ao fator nutrição mineral poderão não ser eficientes. Em estudos com diferentes concentrações de inóculo de C. lindemuthianum em feijoeiro, observou-se aumento da severidade da antracnose nas folhas com o aumento da densidade de inóculo de $1,3 \times 10^{1}$ para $10^{5}$ conídios/ml sendo a severidade máxima encontrada em plantas inoculadas com $10^{5}$ conídios/ml (Dillard \& Cobb, 1993), porém não foi observada a relação com outros nutrientes ou elementos minerais.

Dentre os elementos minerais estudados, o silício (Si) contribuiu para a redução da intensidade de doenças em várias culturas. Pozza et al. (2004) observaram redução de 63,2\% de folhas de café (Coffea arabica L.) lesionadas por Cercospora coffeicola Berkeley \& Cooke, e de $43 \%$ no total de lesões por plantas quando se empregou $1 \mathrm{~g}$ de silicato de cálcio incorporado em $1 \mathrm{~kg}$ de substrato. No mesmo trabalho, utilizando-se a microanálise de raios-X, verificaram maior quantidade de silício nas folhas de plantas tratadas com silicato de cálcio do que nas não tratadas. Plantas de soja (Glycine max L.) cultivadas em solução nutritiva com 40 $\mathrm{mg} / \mathrm{l}$ de Si, apresentaram redução na intensidade do cancro da haste [Diaporthe phaseolorum (Cke \& Ell. Sacc.) var. meridionalis (Morgan-Jones)] reduzindo o número de lesões em até 90\% (Lima, 1998). Juliatti et al. (1996) verificaram a redução da infecção por cancro da haste em diferentes cultivares de soja pela aplicação de wollastonita via solo. Resultados promissores, no controle do oídio [Sphaerotheca fuliginea (Schlecht.:Fr) Poll.], também foram encontrados em plantas de pepino (Cucumis sativus L.), cultivadas em solução nutritiva, suplementada com $100 \mathrm{mg} \cdot \mathrm{kg}^{-1}$ de silicato de potássio (Samuels et al., 1991). Esses autores observaram redução no crescimento das colônias de oídio nas folhas das plantas tratadas, atribuída a presença de silício ao redor das hifas.

Portanto, com base nessas informações, o efeito de diferentes concentrações de inóculo e de duas fontes de silicato na intensidade da antracnose do feijoeiro foi avaliado, juntamente com a observação microscópica de possíveis mecanismos de resistência associados.

\section{MATERIAL E MÉTODOS}

\section{Instalação e condução dos experimentos}

Três experimentos foram instalados e conduzidos em casa de vegetação do Departamento de Fitopatologia da Universidade Federal de Lavras, Lavras-MG, localizado na altitude de $918 \mathrm{~m}$, latitude sul de $21^{\circ} 14^{\prime}$, longitude oeste de $45^{\circ} 00^{\prime}$. O primeiro experimento, conduzido no período de fevereiro a abril de 2004, envolveu o estudo do silicato de cálcio em plantas inoculadas com diferentes concentrações de inóculo de $C$. lindemuthianum. O segundo experimento foi realizado de abril a junho de 2004, para determinar os efeitos de fontes de silicato na redução da antracnose do feijoeiro. O terceiro experimento, visando avaliar e esclarecer o efeito do Si no mecanismo de resistência de plantas foi conduzido no período de março a abril de 2004, no Laboratório de Microscopia Eletrônica e Análise ultraestrutural (LME) do Departamento de Fitopatologia da UFLA e no Laboratório do Núcleo de Apoio à Pesquisa em Microscopia Aplicada a Pesquisa Agropecuária (NAP/ MEPA) na Universidade de São Paulo (USP) localizado em Piracicaba-SP.

Antes de instalar os experimentos, encaminhou-se ao Departamento de Ciência do Solo da Universidade Federal de Lavras, amostra de solo para análise físico-química. O silicato de cálcio ( $\mathrm{CaO}$ - 18\%, SiO - 63\%) e o óxido de cálcio $(\mathrm{CaO})$ foram incorporados ao solo. Esse solo foi acondicionado em sacos plásticos transparentes dentro dos vasos, irrigado com até $60 \%$ da sua capacidade-de-campo e incubado por dez dias. A adubação, de acordo com os resultados da análise, foi aplicada na forma de solução nutritiva e os nutrientes misturados ao solo antes do plantio das sementes.

Foram utilizadas sementes da cultivar Carioca, provenientes da Embrapa Milho e Sorgo, tendo sido colocadas cinco sementes por vaso de $3 \mathrm{l}$ e, após sete dias da emergência das plântulas, procedeu-se o desbaste, permanecendo as duas plântulas mais vigorosas no terceiro experimento e quatro plântulas para os experimentos 1 e 2 . A temperatura e a umidade relativa do ar foram monitoradas termohigrógrafo.

Para obter o inóculo, a cultura monospórica de $C$. lindemuthianum, raça 81, em meio M3, foi multiplicada em vagens de feijoeiro, em tubos de ensaio contendo meio ágar água e mantidos na BOD a $21{ }^{\circ} \mathrm{C} \pm 1{ }^{\circ} \mathrm{C}$ durante dez dias. Esses tubos inicialmente foram autoclavados por três dias consecutivos durante $1 \mathrm{~h}$ a $120{ }^{\circ} \mathrm{C}$ e no quarto dia foi realizada a inoculação nas vagens. Após o crescimento micelial, foi adicionada água destilada nos tubos para obter a suspensão de inóculo, que foi filtrada em gaze dupla. As diferentes concentrações de inóculo foram aferidas em hemacitômetro.

No primeiro experimento, o delineamento experimental utilizado foi em blocos casualizados, com oito tratamentos, quatro repetições e quatro plantas por parcela. Os tratamentos foram constituídos de suspensões com diferentes concentrações de inóculo $\left(0,10^{3}, 10^{4}, 5 \times 10^{4}, 10^{5}, 5 \times 10^{5}, 10^{6}\right.$ conídios/ml de água). Em todos esses tratamentos foi incorporado o silicato de cálcio, na dose de 1,89 g de $\mathrm{SiO}_{2}$ por kg de solo. A testemunha compreendeu o solo sem silicato de cálcio. O teor de cálcio da testemunha foi compensado por óxido de cálcio $\left(1,76 \mathrm{~g} . \mathrm{kg}^{-1}\right.$ de $\left.\mathrm{CaO}\right)$ incorporado ao solo e a mesma foi inoculada com $10^{6}$ conídios/ml de água. Essa concentração de inóculo, para a testemunha, foi escolhida devido a maior probabilidade de se obter alta intensidade da doença e conseqüentemente 
proporcionar a comparação dos efeitos do silicato separado do íon acompanhante, cálcio, no controle da antracnose.

Para avaliar fontes de Si, no experimento 2, utilizouse o delineamento experimental em blocos casualizados, com cinco tratamentos, quatro repetições e quatro plantas por parcela. Os tratamentos foram: plantas suplementadas com silicato de cálcio $\left(1,89 \mathrm{~g}\right.$ de $\mathrm{SiO}_{2} \cdot \mathrm{kg}^{-1}$ de solo obtido do $\left.\mathrm{CaSiO}_{3}\right)$ via solo; silicato de sódio $\left(1,26 \mathrm{~g}\right.$ de $\mathrm{SiO}_{2} \cdot{ }^{-1}$ de água, obtido do $\mathrm{Na}_{2} \mathrm{SiO}_{3}$ ) via foliar, pulverizado três dias antes da inoculação e aos dez e 20 dias após; óxido de cálcio via solo (1,76g de $\mathrm{CaO} . \mathrm{kg}^{-1}$ de solo); plantas com adubação tradicional, de acordo com a recomendação descrita por Malavolta et al. (1997) e por fim a testemunha absoluta com adubação tradicional, porém sem inoculação do patógeno. $\mathrm{O}$ pH da suspensão água destilada + silicato de sódio, foi ajustado para 5,0 adicionando-se ácido clorídrico ( $\mathrm{HCl})$. Utilizou-se pulverizador manual com capacidade para $500 \mathrm{ml}$.

As inoculações, nos experimentos 1 e 2, foram realizadas aos 25 dias após a semeadura (estádio v4, $3^{\mathrm{a}}$ folha trifoliolada) com pulverizador manual (500 ml) contendo $10^{5}$ conídios/ml de água. A pulverização da suspensão foi realizada até o ponto de escorrimento. Em seguida, foi realizada câmara úmida, com saco plástico transparente, por $14 \mathrm{~h}$.

No terceiro experimento, foram utilizados como tratamentos: plantas suplementadas com silicato de cálcio (1,89 g de $\mathrm{SiO}_{2}$ por kg de solo) via solo; com silicato de sódio (1,26 g de $\mathrm{SiO}_{2}$ por litro de água) via foliar, aplicado aos três dias antes da inoculação; com óxido de cálcio $(\mathrm{CaO})$ via solo e plantas somente com adubação tradicional.

Para obter as amostras para microscopia eletrônica, foram destacadas cinco folhas do feijoeiro por tratamento, as quais foram acondicionadas sobre papel umedecido, em bandejas plásticas. Após a inoculação, as bandejas foram fechadas com saco plástico mantendo a umidade elevada. Para facilitar a localização do patógeno, quatro círculos de 0,5 cm de diâmetro foram marcados, com o auxílio de uma caneta esferográfica, em cada folha a ser inoculada. Dentro de cada círculo foram colocados $40 \mu \mathrm{l}$ da suspensão de inóculo ( $10^{5}$ conídios/ml). Foram coletados fragmentos do limbo foliar de 9 mm² após 6, 12, 18, 36 e 48 h da inoculação.

Para observação no microscópio eletrônico de varredura (MEV), 16 fragmentos do limbo foliar de cada tratamento foram imersos em solução fixativa, $\mathrm{pH} 7,2$, e armazenados em geladeira. Em seguida, oito amostras foram lavadas com tampão cocodilato $(0,05 \mathrm{M})$ por três vezes durante $10 \mathrm{~min}$. As secções obtidas foram transferidas para uma solução de tetróxido de ósmio 1\% em água por 2 h e subseqüentemente desidratadas em uma série de acetona (30, 50, 70, 90 e 100\% por três vezes) e depois levadas para o aparelho de ponto crítico. Os espécimes obtidos foram montados em suportes de alumínio "stubs".

Com auxílio de uma fita de carbono, os espécimes foram colocados sobre "stubs" revestidos por uma película de papel alumínio, cobertos com ouro e observados em microscópio eletrônico de varredura LEO Evo 40. Diversas imagens das amostras foram registradas digitalmente, em aumentos variáveis e, gravadas no Software Photopaint do pacote Corel Draw 9 (Alves, 2004).

As amostras para microanálise de raios-X (MAX) foram preparadas com oito fragmentos das mesmas folhas utilizadas para a observação em MEV. As amostras foram lavadas três vezes com água destilada e secadas em estufa por $40 \mathrm{~min}$ a $70{ }^{\circ} \mathrm{C}$. Posteriormente, os espécimes foram montados em suportes de alumínio “stubs”, sendo que metade destes, foi montado com a face superior voltada para cima e a outra metade com a face inferior voltada para cima. Estes espécimes foram levados para o dessecador contendo sílica gel, onde permaneceram por $24 \mathrm{~h}$. Em seguida, foram levados ao aparelho ‘sputtering' (MED 010, Balzer) e cobertos com uma fina camada de carbono. Em seguida as amostras foram observadas em MEV (DSM940-Zeiss, acoplado ao sistema de MAX: EDS-OXFORD INSTRUMENT Link ISIS) onde se verificou os elementos presentes.

\section{Avaliações da doença e análise estatística}

Nos experimentos 1 e 2, as avaliações foram realizadas a cada cinco dias a partir da inoculação. As variáveis avaliadas foram incidência e severidade da doença e área foliar. A incidência foi avaliada pela porcentagem de plantas com sintomas de antracnose na parcela, constituída de vasos com quatro plantas, e pelo número de folíolos por planta com sintomas. A severidade da antracnose foi quantificada com a escala diagramática de Pastor Corralez (Tamoyo, 1995).

Após o término das avaliações, os dados foram integrados ao longo do tempo, obtendo-se a área abaixo da curva de progresso da incidência (AACPI) e da severidade (AACPS), segundo Campbell \& Madden (1990).

A área foliar foi obtida por meio da equação de Iamauti (1995), AF=2,37 x ${ }^{1,9642}-2,7013$, onde AF é a área da folha trifoliolada, em $\mathrm{cm}^{2}$, e x é a maior largura do folíolo central, em cm. O índice de área foliar (IAF) foi calculado a partir dos valores da área foliar de cada planta em relação a área do vaso. Para relacionar a curva de progresso da doença e o crescimento da planta, foi calculada a duração da área foliar sadia (HAD) de acordo com Bergamin Filho et al. (1997).

As variáveis significativas no teste $\mathrm{F}$ das análises de variância foram submetidas ao ajuste de modelos de regressão quando quantitativas e ao teste de médias de ScottKnott quando qualitativas. Foi realizado contraste entre os tratamentos com a maior concentração de inóculo com o uso do silicato de cálcio e o óxido de cálcio, no experimento 2. A análise foi realizada no programa SISVAR, versão 4.3 (Build 45) e os gráficos no programa ORIGIN, versão 7.0.

\section{RESULTADOS E DISCUSSÃO}

A temperatura máxima média durante a condução do primeiro e do segundo experimento foi de $24^{\circ} \mathrm{C}$ e a mínima de $23{ }^{\circ} \mathrm{C}$ e de 21 e $19{ }^{\circ} \mathrm{C}$, respectivamente. A 
umidade relativa média oscilou entre 73 e 64\% no primeiro experimento e entre 75 e 68\%, no segundo. Ambas as variáveis mantiveram-se dentro do intervalo favorável a doença.

No experimento 1 , as respostas à inoculação de diferentes concentrações de inóculo de C. lindemuthianum em plantas suplementadas com silicato de cálcio, quanto a AACPI, a AACPS e a HAD diferiram estatisticamente. Observou-se aumento da AACPI (Figura 1A) e da AACPS (Figura 1B) da doença com o aumento da concentração de inóculo, empregando-se o silicato do cálcio no solo. Relação inversa foi observada para a duração da área foliar sadia (Figura 1C). Em maiores concentrações de inóculo, serão necessárias maiores doses de silicato, outra fonte de maior solubilidade ou outra forma de aplicação para controlar a doença. Neste experimento, plantas não inoculadas apresentaram sintomas da doença (Figura 1A), porém, com baixa intensidade, provavelmente devido à proximidade entre as unidades experimentais.

Outros autores também observaram aumento na intensidade da antracnose e na redução da HAD com o aumento da concentração de inóculo de C. lindemuthianum. Em estudos com plantas de feijoeiro inoculadas com 1,3x10 ${ }^{1}$, $10^{2}, 10^{3}, 10^{4}$ e $10^{5}$ conídios de $C$. lindemuthianum/ml, Dillard \& Cobb (1993) também observaram aumento na severidade da doença nas folhas com o aumento da concentração de inóculo entanto, a severidade encontrada pelos autores foi superior a do presente trabalho. Nunes \& Bergamin Filho (1996) no mesmo patossistema, também verificaram o aumento da severidade da antracnose e redução da HAD, com o aumento das concentrações de inóculo $\left(0,10^{2}, 10^{4}\right.$ e $10^{6}$ conídios $\left./ \mathrm{ml}\right)$. No entanto, tanto a incidência quanto a severidade foram superiores a do presente trabalho.

As plantas com silicato apresentaram menor AACPI e AACPS quando comparadas ao tratamento com $\mathrm{CaO}$, inoculadas com a maior concentração de inóculo, ou seja, $10^{6}$ conídios/ml (Tabela 1), evidenciando o efeito do Si em reduzir a intensidade da antracnose. Resultados semelhantes foram observados em plantas de abóbora suplementadas com $\mathrm{CaCO}_{3}$ e $\mathrm{CaSiO}_{3}$ por Heckman et al. (2003). Esses autores verificaram redução de $83 \%$ no número de lesões de $S$. fuliginea (oídio) e de $48 \%$ na incidência da doença em plantas tratadas com silício no solo, em relação às plantas tratadas com $\mathrm{CaCO}_{3}$. Em cucurbitáceas [pepino (Cucumis sativus L.), melão (Cucumis melo L.), abóbora (Cucurbita moschata Duch) e abobrinha (Cucurbita pepo L.)] tratadas com silicato de potássio, hidróxido de potássio e ácido fosfórico via foliar, Menzies et al. (1992) e Juliatti \& Korndörfer (2003) também observaram o efeito do silicato de potássio na redução no número de colônias de $S$. fuliginea. No segundo experimento, não houve diferença significativa quanto a AACPI da antracnose entre as duas fontes de silício. Em mudas de cafeeiro (Coffea arabica L.), suplementadas com silicato de cálcio e silicato de sódio, também não se observaram diferenças entre as fontes de Si na área abaixo da curva de progresso da incidência (Santos, 2002).

No segundo experimento, observaram-se diferenças estatísticas para a AACPS (Figura 2A), o tratamento com silicato de sódio (T2) diferiu dos demais, teve menor AACPS $(44,2)$ igualando-se à testemunha não inoculada (T5), a qual, não foi contaminada e teve AACPS nula.

Também se observou redução de 62,4\% na severidade da antracnose em relação à testemunha inoculada (T4). Rodrigues et al. (2001), em plantas de arroz (Oryza sativa L.) suplementadas com silicato de cálcio também observaram
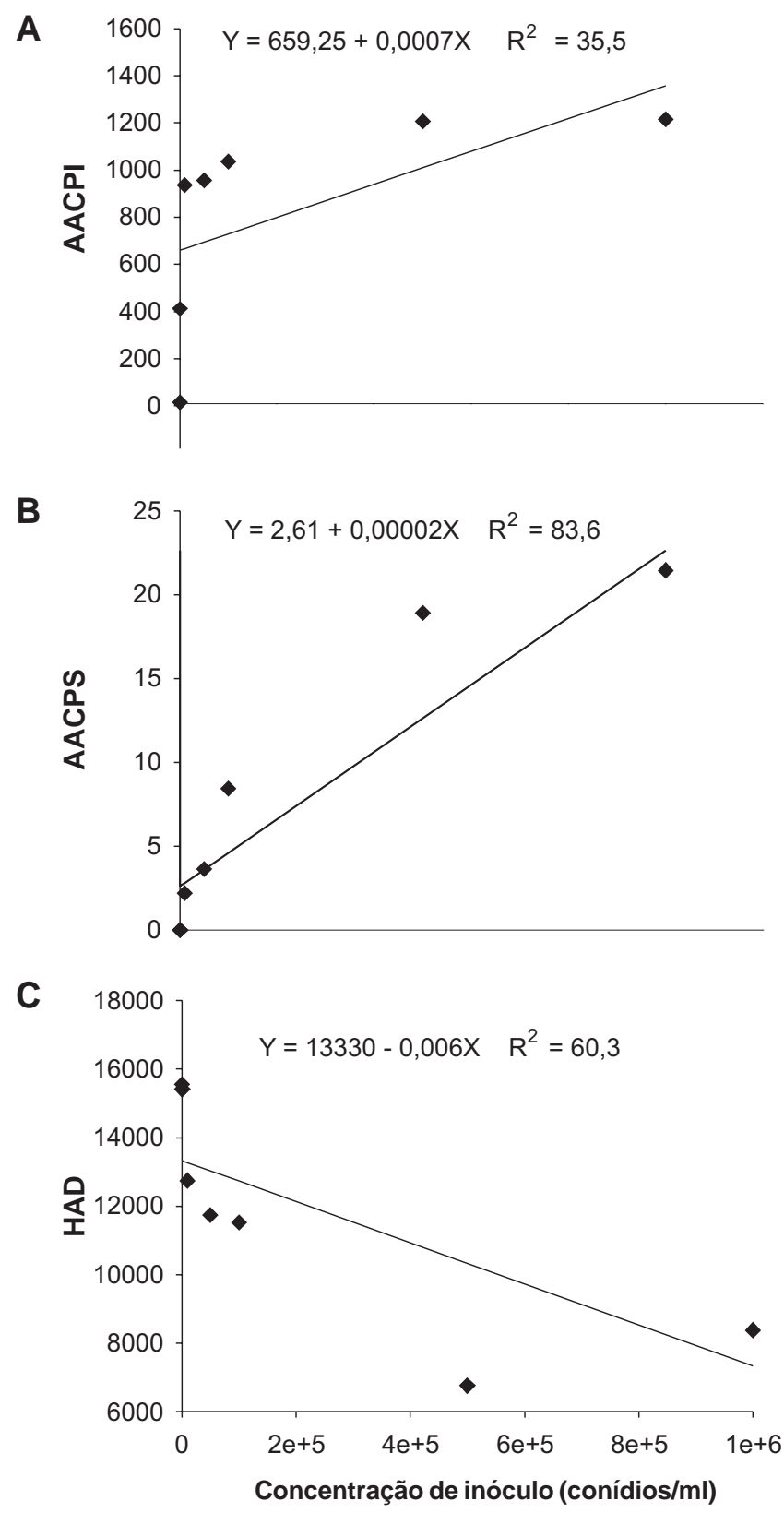

FIG. 1 - (A) Área abaixo da curva de progresso da incidência (AACPI) da antracnose; (B) Área abaixo da curva de progresso da severidade (AACPS); (C) Duração da área foliar sadia (HAD) em função das concentrações de inóculo de Colletotrichum lindemuthianum em plantas de feijoeiro (Phaseolus vulgaris) suplementadas com silicato de cálcio. 
redução na intensidade da doença. Segundo os autores a deposição de Si nas folhas proporcionou redução na extensão das lesões, bem como, menor severidade da doença. Resultados semelhantes foram encontrados por Juliatti et al. (1996) em relação ao uso da fonte wollastonita via solo e a redução na severidade do cancro da haste da soja.

Pode-se observar maior valor da AACPS em relação ao primeiro experimento, provavelmente, devido à ocorrência de baixas temperaturas, favoráveis à doença, durante este experimento.

Resultados semelhantes foram observados em videira (Vitis vinifera L.) suplementada com aplicação foliar e via solução nutritiva de silicato de potássio. Em plantas crescidas em solução nutritiva, com $0,1 \mathrm{~g}$ de Si.l. ${ }^{-1}$, não houve redução na severidade do oídio, causado por Uncinula necator (Schwein.) Burril, entretanto, o silicato de potássio aplicado via foliar (1g de Si.l-1) reduziu a severidade em 14 e 9\% no primeiro e segundo experimentos, respectivamente. Os autores atribuíram essa redução à deposição de Si ao redor do apressório tornando-se o responsável por impedir a penetração do patógeno (Bowen et al., 1992).

As maiores HAD foram obtidas nos tratamentos com $\mathrm{Na}_{2} \mathrm{SiO}_{3}$ (T2) e na testemunha sem inoculação do patógeno (T5), as quais não diferiram entre si, pelo teste de ScottKnott (5\%) (Figura 2B). Esse aumento foi devido a menor severidade da doença em T5, e a ausência da mesma, na testemunha absoluta sem inoculação, demonstrando a capacidade do silicato de sódio em reduzir a AACPS e conseqüentemente aumentar a HAD. A redução da HAD devido a antracnose foi observada por Silva et al. (1998), no entanto essa variável não foi comparada quando foi adicionado silicato ao solo.

No terceiro experimento, na MAX verificou-se maior quantidade de silício em folhas de plantas suplementadas com o elemento (Figuras 3C e 3D), indicando a sua absorção e translocação no feijoeiro, embora o feijoeiro não seja classificado como planta acumuladora (Ma et al., 2001).

Destacaram-se com o maior pico de Si, as plantas pulverizadas com silicato de sódio (Figura 3D). Essa maior absorção, nas plantas em que o Si foi aplicado na forma de silicato de sódio, comparada com a de silicato de cálcio, observada na MAX, pode ser devida a maior solubilidade do silicato de sódio em água, favorecendo sua absorção e também ao fato deste ter sido aplicado via foliar favorecendo

TABELA 1 - Médias da área abaixo da curva de progresso da incidência (AACPI) e severidade (AACPS) da antracnose em plantas de feijoeiro (Phaseolus vulgaris) inoculadas com $10^{6}$ conídios/ml de Colletotrichum lindemuthianum e suplementadas com silicato de cálcio e óxido de cálcio

\begin{tabular}{lcl}
\hline \hline Fonte de Cálcio & AACPI & AACPS \\
\hline Silicato de cálcio & $1214,78 \mathrm{~B}^{1}$ & $21,43 \mathrm{~B}$ \\
Óxido de cálcio & $1444,07 \mathrm{~A}$ & $33,57 \mathrm{~A}$ \\
\hline
\end{tabular}

${ }^{1}$ Médias seguidas de letras diferentes nas colunas, diferem estatisticamente entre si pelo teste $\mathrm{F}$ ( $\mathrm{Pd} " 0,05)$.
A

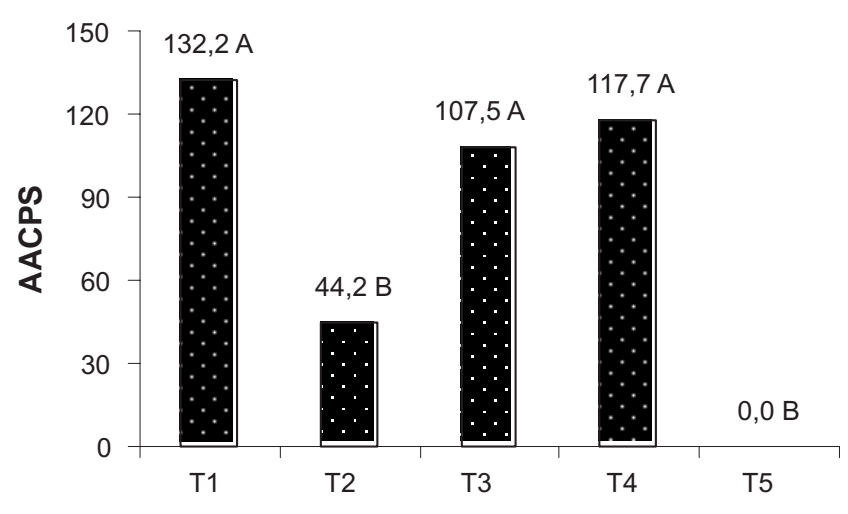

B

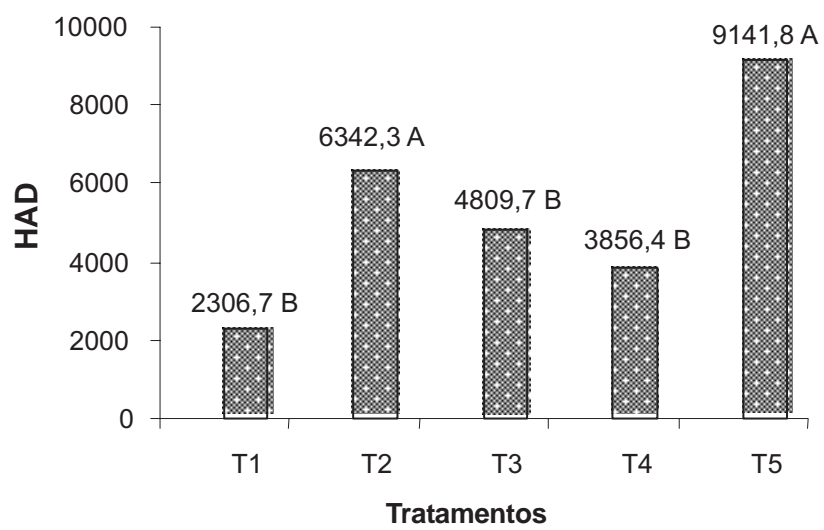

FIG. 2 - (A) Área abaixo da curva de progresso da severidade (AACPS) da antracnose do feijoeiro (Phaseolus vulgaris); (B) Duração da área foliar sadia (AFS) nos cinco tratamentos: $\mathrm{CaSiO}_{3}$ (T1), $\mathrm{Na}_{2} \mathrm{SiO}_{3}$ (T2), $\mathrm{CaO}$ (T3), testemunha inoculada (T4) e testemunha absoluta (T5). (Letras distintas representam diferenças significativas ao nível de 5\% pelo teste Scott-Knott).

sua detecção via MAX. O Si encontrado na testemunha e nas plantas tratadas com óxido de cálcio (Figuras 3A e 3B), embora em pequena quantidade, deve-se possivelmente à contaminação do substrato com o elemento, pois sendo, o Si o segundo elemento mais abundante na superfície terrestre espera-se que ele esteja presente em vários substratos, tornando difícil seu isolamento completo.

Diferença significativa não foi verificada, quanto à presença de cálcio nas folhas (Figura 3), no entanto, observou-se maior quantidade do elemento sódio em folhas pulverizadas com silicato de sódio.

Por meio de MEV, não se observou a formação de camada de cera tanto na superfície abaxial quanto na adaxial das plantas tratadas com silício nas condições avaliadas. Entretanto, em plantas de cafeeiro suplementadas com $1 \mathrm{~g}$ de silicato de cálcio por kg de substrato, observou-se com o uso de MEV acoplada a MAX, a cutícula mais espessa na superfície inferior da folha, principalmente devido à camada de cera epicuticular mais desenvolvida, cobrindo parcialmente os estômatos (Pozza et al., 2004). Em plantas de pepino 

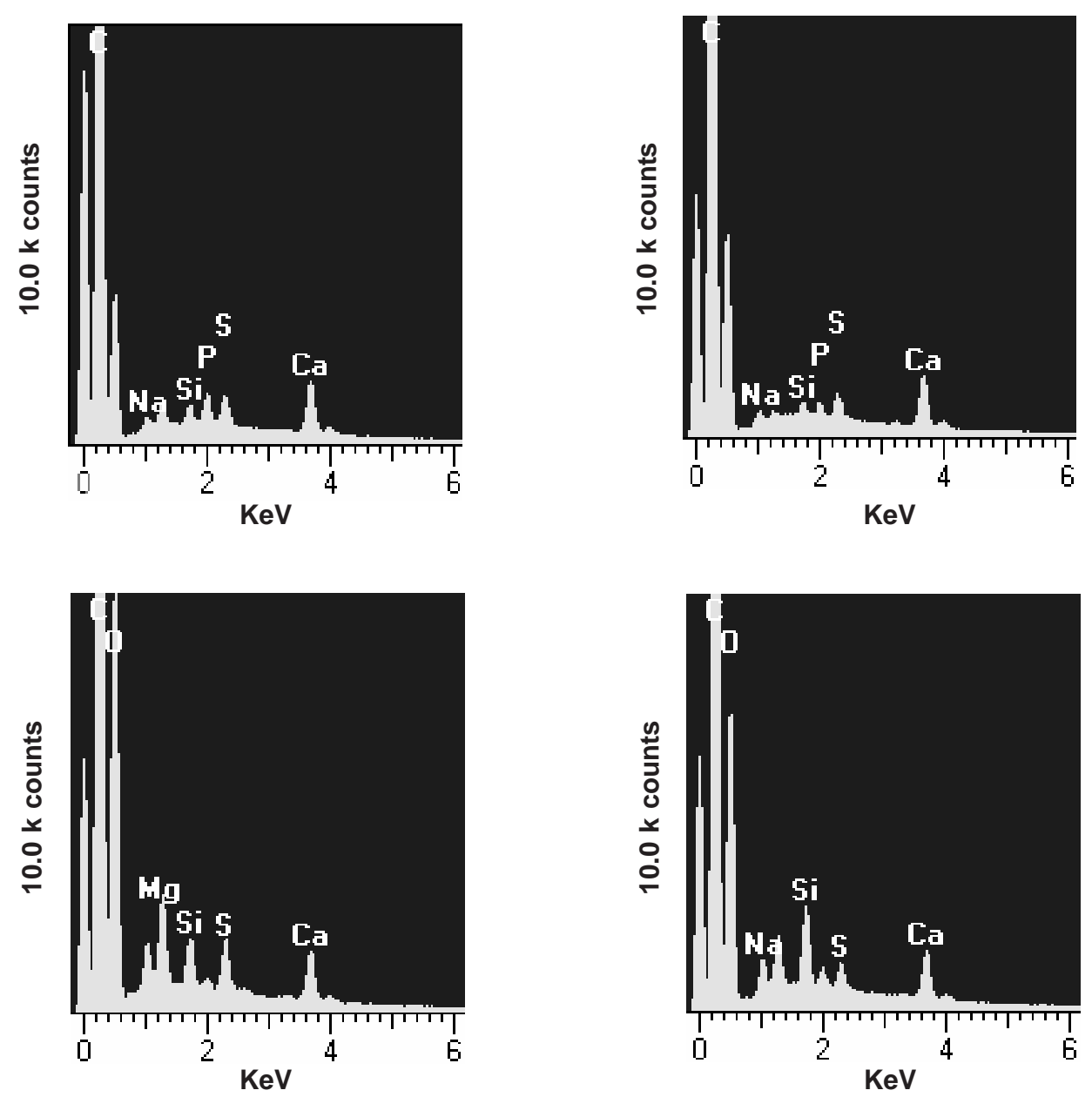

FIG. 3 - Microanálise de Raios-X da superfície inferior de folhas de feijoeiro (Phaseolum vulgaris) nos quatro tratamentos: (A) Testemunha; (B) Óxido de cálcio, aplicado via solo; (C) Silicato de cálcio, aplicado via solo; (D) Silicato de sódio, pulverizado na superfície adaxial e abaxial das folhas.

suplementadas com $0,1 \mathrm{~g} \mathrm{~kg}^{-1}$ de solo de silicato de potássio, Samuels et al. (1991a) observaram o depósito de Si na base do tricoma, ao redor das hifas e dos conidióforos de $S$. fuliginea. Em estudos realizados na superfície de folhas

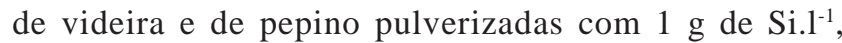
também foi observado o acúmulo de $\mathrm{Si}$, de maneira a constituir barreira física e impedir o crescimento das hifas de U. necator (Bowen et al., 1992) e S. fuliginea (Samuels et al., 1991b).

Dessa maneira, por não ser detectada barreira física externa nas condições avaliadas, novos estudos devem ser realizados, principalmente avaliando-se as enzimas e substâncias relacionadas à resistência nesse patossistema, além da estrutura da parede celular, quando emprega-se o Si.

\section{REFERÊNCIAS BIBLIOGRAFICAS}

ALVES, E. Introdução à Microscopia Eletrônica de Varredura Lavras. Editora UFLA/FAEPE. (Texto Acadêmico). 2004.
BERGAMIN FILHO, A., CARNEIRO, S.M.T.P.G., GODOY, C.V., AMORIN, R.D., BERGER, R.D. \& HAU, B. Angular leaf spot of Phaseolus beans: relationships between disease, healthy leaf area and yield. Phytopathology 87:506-515. 1997.

BOWEN, P., MENZIES, J. \& EHRET, D. Soluble silicon spray inhibit powdery mildew development on grape leaves. Journal of the American Society for Horticultural Sciences, 117:906-912. 1992.

CAMPBELL, C.L. \& MADDEN, L.V. Introduction to plant disease epidemiology. New York. John Wiley \& Sons Inc. 1990.

CHAVES, G. Antracnose. In: Shwartz, H.F. \& Galvez, G.E. (Eds.). Bean production problems: disease, insect, soil and climatic of Phaseolus vulgaris. Cali. Centro International de Agricultura Tropical. 1980.

DILLARD, H.R. \& COBB, A.C. Survival of Colletotrichum lindemuthianum in bean debris in New York State. Plant Disease 77:1233-1238. 1993.

HECKMAN, J. R., JOHNSTON, S. \& COWGILL, W. Pumpkin yield and disease response to amending soil with silicon. HortScience 38:552-554. 2003.

IAMAUTI, M. T. Avaliação de danos causados por Uromyces 
appendiculatus no feijoeiro. (Tese de Doutoado). Piracicaba. ESALQ/USP. 1995.

JULIATTI, F.C. \& KORNDÖRFER, G.H. Uso do silício no manejo integrado de doenças de plantas-Experiência brasileira. Fitopatologia Brasileira. 28:S45-S52. 2003. (Suplemento)

JULIATTI, F.C., RODRIGUES, F.A., KORNDÖRFER, G.H., SILVA, O.A., CORREA,G.F. \& PEIXOTO, J.R. Efeito da aplicação de silício na indução de resistência a Diaporthe phaseolorum f. sp. meridionalis em cultivares de soja com diferentes níveis de resistência. Fitopatologia Brasileira. 21:S51. 1996. (Suplemento)

LIMA, M.T.G. de. Interrelação Cancro da haste (Diaporthe phaseolorum f. sp. meridionalis), nodulação (Bradyrhizobium japonicum) e silício em soja [Glycine Max (L.) Merrill]. (Tese de Doutorado). Piracicaba. Centro de Energia Nuclear na Agricultura, ESALQ/USP. 1998.

MA, J.F., MIYAKE, Y. \& TAKAHASHI, E. Silicon as a beneficial element for crop plants. In: Datnoff, L.E., Snyder, G.H. \& Korndörfer, G.H. (Eds.). Silicon in Agriculture. Amsterdam. Elsevier Science. 2001. pp.17-39

MALAVOLTA, E., VITTI, G.C. \& OLIVEIRA, S.A. Avaliação do estado nutricional das plantas: princípios e aplicações. 2 ed. Piracicaba. POTAFOS. 1997.

MENZIES, J., BOWEN, P., EHRET, D. \& GLASS, A.D.M. Foliar applications of potassium silicate reduce severity of powdery mildew on cucumber, muskmelon, and zucchini squash. Journal of the American Society for Horticultural Sciences. 117:902-905. 1992.

NUNES, W.M.C. de \& BERGAMIN FILHO, A. Avaliação dos danos causados pela antracnose (Colletotrichum lindemuthianum) do feijoeiro. Fitopatologia Brasileira 21:436-442. 1996.

POZZA, A.A., ALVES, E., POZZA, E.A., CARVALHO, J.G. de, MONTANARI, M., GUIMARÃES, P.T.G. \& SANTOS, D.M. Efeito do silício no controle da cercosporiose em três variedades de cafeeiro. Fitopatologia Brasileira 29:185-188. 2004.

SAMUELS, A.L., GLASS, A.D.M., EHRET, D.L. \& MENZIES, J.G. Mobility and deposition of silicon in cucumber plants. Plant, Cell and Environment 4:485-492. 1991a.

SAMUELS, A.L., GLASS, A.D.M., EHRET, D.L. \& MENZIES, J.G. Distribution of silicon leaves during infection by powdery mildew fungus (Sphaerotheca fuliginea). Canadian Journal Botanical. 69:140-146. 1991b.

SANTOS, D.M. Efeito do silício na intensidade da cercosporiose (Cercospora coffeicola Berk. \& Cooke) em mudas de cafeeiro (Coffea arabica L.). (Tese de Mestrado). Lavras. Universidade Federal de Lavras. 2002.

SILVA, M.B., VALE, F.X.R., ZAMBOLIM, L. \& HAU, B. Efeitos da ferrugem, da antracnose e da mancha-angular na área foliar de plantas de feijoeiro em condições de campo. Fitopatologia Brasileira 23:442-447. 1998.

RODRIGUES, F.A., DATNOFF, L.E., KORNDORFER, G.H., SEEBOLD, K.W. \& RUSH, M.C. Effect of silicon and host resistance on sheath blight development in rice. Plant Disease 85:827-832. 2001.

TAMOYO, P.J. Manejo y control de las enfermedades del fríjol voluble. Río Negro. Peloto. 1995. 